\title{
Antihypertensive Effects of Osteospermum Imbricatum in Two Hypertensive Rat Models
}

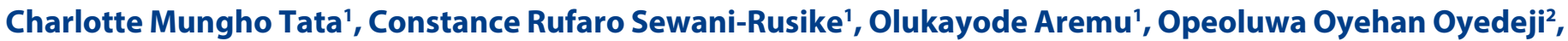 \\ Benedicta Ngwenchi Nkeh-Chungag ${ }^{3, *}$
}

\section{Charlotte Mungho Tata', Constance Rufaro Sewani- Rusike', Olukayode Aremu', Opeoluwa Oyehan Oyedeji ${ }^{2}$, Benedicta Ngwenchi Nkeh- Chungag ${ }^{3, *}$}

'Department of Human Biology, Faculty of Health Sciences, Walter Sisulu University, Mthatha 5117, SOUTH AFRICA.

${ }^{2}$ Department of Chemistry, Faculty of Science and Agriculture, University of Fort Hare, PBX1314 Alice, 5700 Eastern Cape Province, SOUTH AFRICA.

${ }^{3}$ Department of Biological and Environmental Sciences, Faculty of Natural Sciences, Walter Sisulu University, Mthatha 5117, SOUTH AFRICA.

\section{Correspondence}

Benedicta N. Nkeh-Chungag

Department of Biological and Environmental Sciences, Faculty of

Natural Sciences, Walter Sisulu University, Mthatha 5117, SOUTH AFRICA.

Phone no: +27726373725;

E-mail: bnkehchungag@wsu.ac.za

History

- Submission Date: 06-10-2020;

- Review completed: 12-11-2020;

- Accepted Date: 30-11-2020.

DOI : 10.5530/pj.2021.13.95

Article Available online http://www.phcogj.com/v13/i3

\section{Copyright}

(C) 2021 Phcogj.Com. This is an openaccess article distributed under the terms of the Creative Commons Attribution 4.0 International license.

\section{ABSTRACT}

Introduction: Osteospermum imbricatum is used traditionally in Eastern Cape, South Africa for the management of hypertension, chest and stomach complaints. This study was aimed at investigating the antioxidant and antihypertensive effects of this plant. Methods: Antioxidant capacity was determined by radical scavenging assays and ferric reducing antioxidant power. Antihypertensive effects after once off treatment with the leaf $/$ root extracts $(500 \mathrm{mg} / \mathrm{kg}$ ) were evaluated in spontaneously hypertensive rats (SHR). The effect of the extracts on established hypertension was determined in Wistar rats treated with $\mathrm{N} \omega$-Nitro-L-arginine methyl ester (L-NAME) $(40 \mathrm{mg} / \mathrm{kg} /$ day) for 4 weeks followed by co-treatment with L-NAME and extracts (200 $\mathrm{mg} / \mathrm{kg}$ and $400 \mathrm{mg} / \mathrm{kg}$ ) or amlodipine $(5 \mathrm{mg} / \mathrm{kg}$ ) or normal saline for 4 more weeks. Results: The concentration at which there was $50 \%$ inhibition $\left(\mathrm{IC}_{50}\right)$ of DPPH radical by the extracts was lower for the leaf extract $(0.79 \mathrm{mg} / \mathrm{mL})$ compared to the root extract $(1.15 \mathrm{mg} / \mathrm{mL})$. The leaf extract significantly $(p<0.01)$ decreased systolic and diastolic blood pressures in both rat models. Conclusion: The extracts of Osteospermum imbricatum have moderate antioxidants and antihypertensive properties.

Key words: Antioxidants, High blood pressure, $\mathrm{N} \omega$-Nitro-L-arginine methyl ester, Spontaneously hypertensive rats.

\section{INTRODUCTION}

Hypertension (HTN) is often referred to as the silent killer with no obvious signs and symptoms though it is the leading cause of most cardiovascular diseases. ${ }^{1}$ The prevalence of HTN is higher in lowand middle-income countries (LMIC) $(31.5 \%)$ than in high-income countries (HIC) (28.5\%) worldwide. Although the mechanisms underlying HTN are not yet fully elucidated, a large amount of evidence shows that oxidative stress plays a central role in its pathophysiology. ${ }^{2}$ Oxidative stress leads to decrease in nitric oxide levels and increase in reactive oxygen species (ROS). ${ }^{3}$ Therefore, induction of HTN by chronic administration of nitric oxide synthase (NOS) inhibitors such as $\mathrm{N} \omega$ Nitro-L-arginine methyl ester (L-NAME) is widely accepted to mimic HTN in humans. ${ }^{4}$ L-NAMEtreated rats have down-regulated eNOS protein expression in blood vessels and depletion of plasma NO levels which leads to systemic vasoconstriction, increased vascular resistance and high blood pressure. ${ }^{5}$ It is well established that this model of HTN is likely to be associated with an increase in peripheral vascular resistance which includes vascular functional/structural changes and cardiac hypertrophy. ${ }^{6}$ Other possible causes of systemic vasoconstriction in NO-deficient rats may include enhancements of sympathetic nerve activity, reninangiotensin system and oxidative stress. ${ }^{6}$

Despite the availability of many classes of medication that lower blood pressure, many patients still fail to comply with treatment due to multiple reasons one of them being adverse drug reactions. ${ }^{7}$ In addition, most of these drugs are not accessible and/or affordable and in many cases, none of them can control HTN singly. ${ }^{8}$ Consequently, combination therapy is often required. Combination therapy however, increases the risk of drug-drug interactions and side effects. Therefore, there is need for the development of new antihypertensive medications.

Plants are potential sources of new medications. South Africa is endowed with a wealth of indigenous plants whose medicinal potentials are yet to be explored. Osteospermum imbricatum ('umashiqolo' in the Xhosa language) is a perennial shrub of the family Asteraceae and indigenous to South Africa and Mozambique. In folk medicine, it is used for treating chest/stomach complaints and internal problems ${ }^{9}$ and traditional healers claim that they used it to treat HTN (unpublished). We conjectured that if oxidative stress is indeed involved in the pathogenesis of HTN, then the control and reduction of oxidative damage by antioxidants should reduce blood pressure. Therefore, this study was aimed at investigating the antioxidant and antihypertensive properties of $O$. imbricatum extracts.

\section{MATERIALS AND METHODS}

\section{Drugs, chemicals and reagents}

$\mathrm{N} \omega$-Nitro-L-arginine methyl ester, 2,2'- azinobis (3-ethylbenzothiazoline-6-sulfonic acid), 1,1-diphenyl-2-picryl-hydrazil, gallic acid, ascorbic acid, trolox and quercertin were obtained from 
Sigma-Aldrich Chemical Co. (St Louis, MO, USA) while furosemide and amlodipine were obtained from Pharmacare Ltd, (South Africa).

\section{Plant collection and extraction}

Plant material was collected from Lusikisiki (Lat: -31.350; Long: 29.583), Eastern Cape Province of South Africa by Mr Fikile Mahlakata. It was authenticated Dr Immelman in the KEI Herbarium of Walter Sisulu University where a voucher specimen (Tata 2/14009) was deposited. Plant material was air-dried at room temperature in the laboratory, crushed and $610 \mathrm{~g}$ of the crushed plant material was submerged in $2.5 \mathrm{~L}$ of $70 \%$ ethanol and extracted by maceration for 72 hours. The ethanol was recovered using a rotary evaporator (Heidolph Laborota 4000, Germany) and the extracts dried in a fan oven at $35^{\circ} \mathrm{C}$. The extracts were reconstituted in distilled water before used.

\section{Animal handling}

Animals were housed in cages in the animal holding facility of Walter Sisulu University which was maintained at $24^{\circ} \mathrm{C}$. Lighting was provided by day light exclusively. The animals had free access to rat chow and water. The ethical clearance (protocol \# 015/15) for the study was approved by the Faculty of Health Sciences Ethical Clearance Committee, Walter Sisulu University, South Africa. All animal procedures were carried out in line with the South African National Standards: The care and use of animals for scientific purposes. ${ }^{10}$

\section{Antioxidant capacity of extract}

\section{Determination of flavonoid and phenolic content}

Flavonoid content was determined as described by Irshad et al. ${ }^{11}$ using quecertin as standard. Phenolic and polyphenolic compounds constitute the main class of natural antioxidants present in plants, foods, and beverages and are usually quantified employing Folin's reagent ${ }^{12}$ using gallic acid as standard.

\section{Radical scavenging activity}

Radical scavenging activity was evaluated by 2 methods; DPPH (1,1-diphenyl-2-picryl-hydrazil) and ABTS (2,2'- azinobis (3-ethylbenzothiazoline-6-sulfonic acid). DPPH assay was done using ascorbic acid as standard. The ability of the extracts to scavenge DPPH radical was calculated as percentage using the formula:

$\%$ Inhibition $=\mathrm{AbsB}-\mathrm{AbsE} / \mathrm{AbsB}{ }^{*} 100$

Where AbsB is absorbance of blank and AbsE is absorbance of sample (extracts or standard).

The inhibitory concentration $\left(\mathrm{IC}_{50}\right.$ ) of extracts needed to inhibit $50 \%$ DPPH radical was extrapolated from the graph of $\%$ inhibition against concentration. ABTS assay was done using trolox as standard. DPPH and ABTS assays were done following the methods as described by Tata et al. ${ }^{13}$

\section{Total antioxidant capacity}

FRAP (Ferric Reducing Antioxidant Power) was done following the methods as described by Tata et al. ${ }^{13}$ using ascorbic acid as standard.

\section{Antihypertensive effects of 0 . imbricatum leaf and root extracts}

The antihypertensive effect of $O$. imbricatum was evaluated in two phases that is; once off treatment phase and 8 weeks treatment phase.

In the once off treatment phase, 24 spontaneously hypertensive rats (SHR) weighing 230-300 g were grouped into four groups of six rats each $(n=6)$ : Group I - normal saline; Group II - leaf extract $(500 \mathrm{mg} /$ $\mathrm{kg})$; Group III - root extract $(500 \mathrm{mg} / \mathrm{kg})$; Group IV - Furosemide (10 $\mathrm{mg} / \mathrm{kg}$ ). The systolic blood pressure (SBP), diastolic blood pressure
(DBP) and heart rates were measured before (at baseline), 2, 4, 6, 8 and 24 hours after treatment. ${ }^{14}$

In the 8 weeks treatment phase, 42 female Wistar rats weighing 200$280 \mathrm{~g}$ were randomized into seven treatment groups of six per group $(\mathrm{n}=6)$ : NT (normotensive control) -normal saline only; LN - normal saline and L-NAME; AMLO -amlodipine $(5 \mathrm{mg} / \mathrm{kg})$ and L-NAME; OIL200 - leaf extract $(200 \mathrm{mg} / \mathrm{kg})$ and L-NAME; OIL400 - leaf extract $(400 \mathrm{mg} / \mathrm{kg})$ and L-NAME; OIR 200 - root extract $(200 \mathrm{mg} / \mathrm{kg})$ and L-NAME; OIR400 -root extract $(400 \mathrm{mg} / \mathrm{kg})$ and L-NAME. Apart from the normotensive (NT) group that was treated with normal saline only, the other groups were first treated with L-NAME $(40 \mathrm{mg} / \mathrm{kg})$ for 4 weeks and then co-treated with L-NAME $(20 \mathrm{mg} / \mathrm{kg})$ and normal saline or amlodipine or extracts for two weeks; and finally with L-NAME (5 $\mathrm{mg} / \mathrm{ml}$ ) and normal saline or amlodipine or extracts for two more weeks making a total of eight treatment weeks. All rats were treated orally and the volumes of extract, drug or L-NAME given for each dose was calculated based on the weight of each rat. Blood pressure was measured weekly between 9 and 16 hours after treatment.

The dose of the L-NAME was decreased after 4 weeks induction in order to sustain HTN in the rats without killing them. The SBP, DBP and heart rates were measured weekly.

\section{Measurement of blood pressure}

Blood pressure was measured in conscious rats, using non-invasive tail-cuff plethysmography (CODA ${ }^{\mathrm{TM}} 8$ Non-Invasive Blood Pressure System, Kent Scientific Corporation, USA) as as described by Tata et al. $^{15}$

\section{Urine output}

Urine output was monitored weekly by placing the rats individually in metabolic cages over a period of 24 hours. Urine was collected in graduated cylinders.

\section{Termination}

Treatment was stopped two days to termination. The rats were fasted for 16 hours, weighed and terminated. The kidneys, heart and liver were harvested and weighed. The percentage organ to body weight ratio was calculated:

$\%$ organ to body weight ratio $=($ weight of organ $/$ body weight $){ }^{\star} 100$.

\section{Statistical analysis}

Statistical analyses were carried out using the Graph Pad Prism version 5.03. Student $\mathrm{t}$-test was used to compare differences in antioxidant activity between leaf and root extracts. One-way analysis of variance (ANOVA) followed by Tukey's test for multiple comparisons were used to determine differences between treatment groups. Results were expressed as mean \pm SEM and $\mathrm{p}<0.05$ was considered significant.

\section{RESULTS}

\section{Antioxidant capacity of $O$. imbricatum}

The leaf extract had higher flavonoid content $(8.96 \pm 0.08 \mu \mathrm{g}$ quecertin equivalent/mg extract) compared to the root extract $(2.25 \pm 0.13 \mu \mathrm{g}$ quercetin equivalent/mg extract). The total phenolic compounds in leaf and root extracts were $3.46 \pm 0.31$ and $1.41 \pm 0.14 \mu \mathrm{g}$ gallic acid equivalents (GAE)/mg extract respectively (Figure 1 ). The total antioxidant capacity of the leaf and root extracts were $82.57 \pm 1.33$ and $67.13 \pm 0.3 \mu \mathrm{g} \mathrm{GAE} / \mathrm{mg}$ extract respectively. The free radical scavenging activity of the leaf and root extracts for the DPPH assay were $41.98 \pm$ $0.2 \mu \mathrm{g}$ ascorbic acid equivalent (AAE) $/ \mathrm{mg}$ extract $\left(\mathrm{IC}_{50} 0.79 \mathrm{mg} / \mathrm{mL}\right.$ ) and $30.38 \pm 0.4 \mu \mathrm{g} A A E / \mathrm{mg}$ extract $\left(\mathrm{IC}_{50} 1.15 \mathrm{mg} / \mathrm{mL}\right.$ ) respectively. The antioxidant activity of the leaf and root extracts for the ABTS assay were 


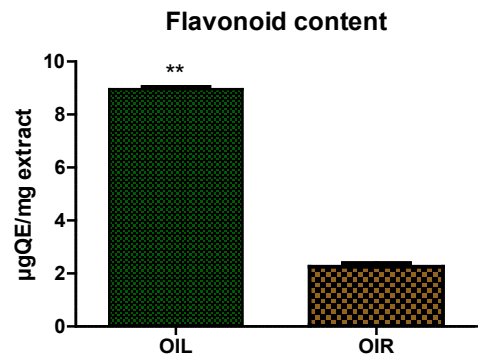

FRAP

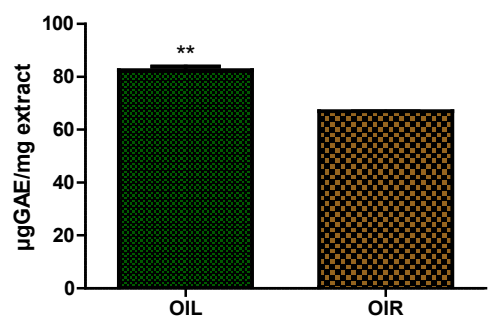

OIL

OIR

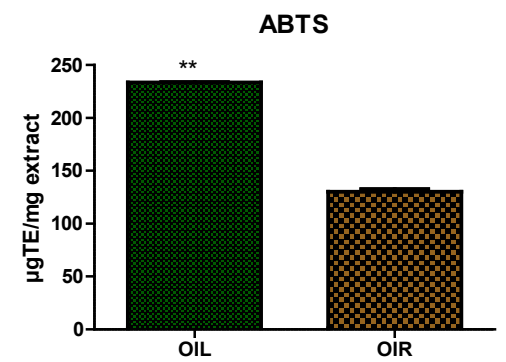

Total Phenolic content

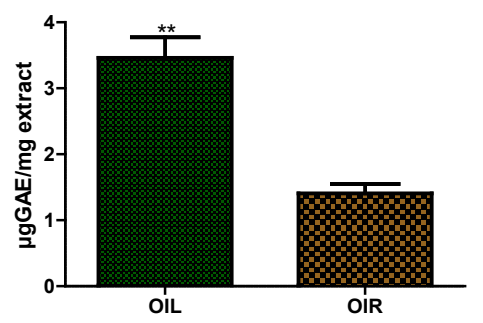

OIL

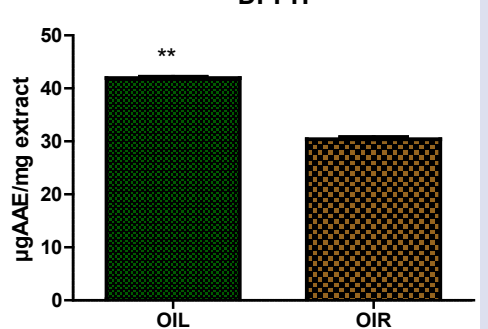

OIL

OIR

Figure 1: Antioxidant Capacity of $O$. imbricatum (QE- quercertin equivalent, GAE- gallic acid equivalent, $\mathrm{AA}$ - ascorbic acid equivalent, TE- trolox equivalent, $\mathrm{OIL}=0$. imbricatum leaf extract, $\mathrm{OIR}=0$. imbricatumroot extract). ${ }^{* *} \mathrm{p}<0.01$.

$233.5 \pm 0.43$ and $130 \pm 2.6 \mu \mathrm{g}$ trolox equivalent/mg extract respectively (Figure 1).

\section{Antihypertensive effect of $O$. imbricatum}

\section{Effect of once-off treatment of spontaneously hypertensive rats with $O$. imbricatum extracts}

The OIL extract significantly reduced SBP by $11.1 \%$ at the fourth hour after treatment. Systolic blood pressure (SBP) remained lower compared to controls (indicated by the negative values of the control percentages) throughout the experimental period. The OIR extract had an earlier onset of anti-hypertensive effects two hour after treatment and lowered SBP by $5.9 \%$ (Table 1 ). The OIL extract significantly decreased DBP from the second to the twenty fourth hour after treatment; the percentage decrease in DBP ranged from 1.3-18.2\% compared to the controls whose BP differences ranged from -7.8 to $2.4 \%$. At the sixth and twenty fourth hour, OIL activity $(5.1 \%$ and $18.2 \%$; $\mathrm{p}<0.05)$ appeared to be significantly higher than the amlodipine $(-0.8$ and $2.4 \%)$. The root extract showed statistically significant reduction of DBP (6 and $8.5 \%)$ compared to control (-2.1 and $-7.8 \%)$ at the second and the fourth hour after treatment respectfully (Table 2 ).

\section{Effects of O. imbricatum leaf and root extracts in L-NAME induced hypertension}

Oral administration of L-NAME $(40 \mathrm{mg} / \mathrm{kg})$ once daily caused a significant rise in BP from the second to the fourth week of administration. Systolic BP and DBP were similar among groups in the first and fourth week of L-NAME administration. Blood pressures from week 4 served as baseline for the treatment weeks (Table 3 and 4). In week 6 and 7 of treatment, the SBP of the treated groups was significantly lower than the L-NAME (LN) control group but higher than the normotensive group (NT). In week 8 , the SBP of the amlodipine (AMLO) group and OIL400 groups were not significantly different from the NT control group and all the groups had BPs lower than that of the LN control group (Table 3). The DBP of the treated groups was only significantly lower than the LN control group in week 8 . The DBP of the Amlodipine treated group was not significantly different from that of the NT group in week 8 (Table 4). 
Table 1: Effect of $O$. imbricatum extracts on systolic blood pressure in spontaneously hypertensive rats.

\begin{tabular}{ccccc}
\hline & \multicolumn{4}{c}{ Treatment groups/Percentage change in SBP (\%) } \\
\hline Time/hrs & NS & Furosemide & OIL & OIR \\
\hline 2 & -4.7 & $9.9^{* *}$ & -2 & $5.9^{* *}$ \\
4 & 1.1 & $9.6^{* *}$ & $11.1^{* *}$ & -1.6 \\
6 & -7.4 & $10.3^{* *}$ & $3.1^{* *}$ & $0.3^{* *}$ \\
8 & -8 & $15.8^{* *}$ & $0.4^{* *}$ & $2.8^{* *}$ \\
24 & -3.8 & $6.7^{* *}$ & $6.4^{* *}$ & -2 \\
\hline
\end{tabular}

Negative values indicate an increase in SBP from baseline values. Percentages were obtained by computing (((SBP at baseline - SBP at given times after treatment)/SBP at baseline) $\times 100) . \mathrm{NS}=$ normal saline; OIL $=0$. imbricatumleaf extract; OIR $=0$. imbricatumroot extract. $n=6 .{ }^{*} p<0.05,{ }^{* *} p<0.01$

Table 2: Effect of $O$. imbricatum extracts on diastolic blood pressure in spontaneously hypertensive rats.

\begin{tabular}{ccccc}
\hline & \multicolumn{4}{c}{ Treatment groups/Percentage change in DBP (\%) } \\
\hline Time/hrs & NS & Furosemide & OIL & OIR \\
\hline 2 & -7.8 & $12^{* *}$ & 1.3 & $8.5^{*}$ \\
4 & -2.1 & $11^{* *}$ & $17.7^{* *}$ & $6^{* *}$ \\
6 & -0.8 & -0.9 & $5.1^{* *}$ & -2.6 \\
8 & 1.9 & $13.4^{* *}$ & $7.6^{*}$ & 2.9 \\
24 & 2.4 & 6 & $18.2^{* *}$ & -8
\end{tabular}

Negative values indicate an increase in DBP from baseline values. Percentages were obtained by computing (((DBP at baseline - DBP at given times after treatment)/DBP at baseline) $\mathrm{x} 100)$. NS = normal saline, OIL = O. imbricatumleaf extract; OIR $=0$. imbricatumroot extract. $\mathrm{n}=6$; ${ }^{*}$ indicates comparisons between treatment groups and normal saline group; \# denotes comparisons between extract treatment groups and Furosemide group. ${ }^{*} \mathrm{p}<0.05 ;{ }^{* *} \mathrm{p} 1<0.01 ;{ }^{*} \mathrm{p}<0.05$

Table 3: Effect of $O$. imbricatum extracts on systolic blood pressure in L-NAME induced hypertension (mmHg).

\begin{tabular}{|c|c|c|c|c|c|c|c|c|}
\hline \multirow{3}{*}{$\begin{array}{c}\text { Treatment } \\
\text { Groups }\end{array}$} & \multicolumn{8}{|c|}{ Time (weeks) } \\
\hline & \multicolumn{4}{|c|}{ L-NAME only } & \multicolumn{4}{|c|}{ L-NAME + treatment } \\
\hline & Wk1 & Wk2 & Wk3 & Wk4 & Wk5 & Wk6 & Wk7 & Wk8 \\
\hline NT & $149 \pm 4$ & $149 \pm 4$ & $153 \pm 3$ & $153 \pm 3$ & $155 \pm 4$ & $155 \pm 4$ & $157 \pm 3$ & $157 \pm 3$ \\
\hline $\mathrm{LN}$ & $151 \pm 1$ & $\underset{\substack{\# \# \\
\text { \#\# }}}{196.3}$ & $\underset{\# \#}{210 \pm 3}$ & $\underset{\substack{\# \# \\
208}}{208}$ & 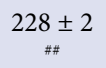 & $\underset{\substack{\# \# \\
\# \#}}{236} 0.3$ & $\underset{\text { \#\# }}{213 \pm 2}$ & $\underset{\# \#}{224 \pm 1}$ \\
\hline AMLO & $154 \pm 2$ & $\underset{\# \#}{197 \pm 3}$ & $\underset{\# \#}{213 \pm 3}$ & $\underset{\# \#}{216 \pm 1}$ & $211 \pm 4$ & $\underset{\star \star \# \#}{185 \pm 3}$ & $\begin{array}{c}174 \pm 2 \\
\star *\end{array}$ & $\begin{array}{c}159 \pm 2 \\
* *\end{array}$ \\
\hline OIL200 & $152 \pm 3$ & $\underset{\# \#}{190 \pm 2}$ & $207 \pm 3$ & $\underset{m \#}{206 \pm 3}$ & $\underset{\# \#}{223 \pm 2}$ & $\underset{* * \# \#}{203 \pm 5}$ & $\underset{\# \#}{203 \pm 3}$ & $\underset{* * \# \#}{182 \pm 4}$ \\
\hline OIL400 & $157 \pm 2$ & 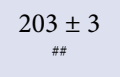 & $\underset{\# \#}{208 \pm 2}$ & 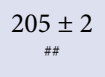 & $\underset{\# \#}{220 \pm 3}$ & $\underset{* * \# \#}{188 \pm 3}$ & $\underset{\star \star * \# \#}{181 \pm 4}$ & $\underset{* * * \#}{168 \pm 4}$ \\
\hline OIR200 & $157 \pm 3$ & $\underset{\# \#}{191 \pm 2}$ & $\underset{\# \#}{208 \pm 1}$ & $\begin{array}{c}214 \pm 2 \\
\# \#\end{array}$ & $\underset{\# \#}{218 \pm 4}$ & $\underset{\star \star \star \# \#}{207 \pm 3}$ & $\underset{\star \star \star \# \#}{189 \pm 4}$ & $\underset{* * \# \#}{197 \pm 5}$ \\
\hline OIR400 & $154 \pm 2$ & $\underset{\# \#}{201 \pm 2}$ & $219 \pm 0.2$ & $\underset{\# \#}{209 \pm 3}$ & $\underset{\# \#}{212 \pm 2}$ & $\underset{* * \# \#}{199 \pm 3}$ & $\underset{* * \# \#}{186 \pm 3}$ & $\underset{* * * \#}{199 \pm 2}$ \\
\hline
\end{tabular}

Values are expressed as mean \pm SEM.NT $=$ normotensive normal saline; LN $=$ L-Name/normal saline; OIL $=$ O. imbricatumleaf extract; OIR $=$ O. imbricatumroot extract; AMLO $=$ amlodipine. $\mathrm{n}=6{ }^{*}{ }^{*}$ indicates comparison between the treatment group and L-NAME (LN) control group; ${ }^{*}$ indicates comparison between the treatment group and normotensive control group $(\mathrm{NT}) .{ }^{*} \mathrm{p}<0.05,{ }^{* *} \mathrm{p}<0.01 ;{ }^{*} \mathrm{p}<0.05,{ }^{* \#} \mathrm{p}<0.01$

Table 5 shows the changes in heart rate during the 8 weeks of study. There was a general decrease in heart rate in all the groups treated with L-NAME $(40 \mathrm{mg} / \mathrm{kg})$ in the first 4 weeks. In the 5 th week, when the dose of L-NAME was reduced to $20 \mathrm{mg} / \mathrm{kg}$, heart rate increased in some groups (LN, OIL200, OIR200) and decreased in others (AMLO, OIR400). Further decrease of the dose of L-NAME in the last two weeks resulted in increased heart rate in all the groups but the increase in the LN group was not significant. Considering week 5 as the baseline for treatment after HTN was induced, it was observed that, there was a significant decrease $(p<0.01)$ in heart rate in the LN group in week 6 while in the AMLO group, there was a significant increase $(\mathrm{p}<0.01)$ in weeks 7 and 8 compared to week 5. OIL200 and OIL400 caused a significant increase $(\mathrm{p}<0.01)$ in heart rate in the 7 th and 8 th week respectively compared to week 5 . The OIR200 had no effect on heart rate while OIR400 caused an increase in heart rate from the 6th to the 8 th week of treatment compared to week 5 .

\section{Effects of O. imbricatum leaf and root extracts on urine output}

Following induction of HTN, urine output in the LN treatment groups was higher compared to all treatment groups. Urine output in the OIL treatment groups increased progressively from $17 \pm 2$ to $20 \pm 1.7$ for OIL200 and14 \pm 1.7 to $19 \pm 1$ for OIL400. Co-treatment of animals with L-NAME and amlodipine or OIL400 tended to correct the diuresis induced by L-NAME treatment. In the final week of treatment urine output in the OIL200, OIL400 and OIR400 treatment groups were statistically higher $(\mathrm{p}<0.01)$ compared to the NT control group but not significantly different from the LN group (Table 6). 
Effects of O. imbricatum leaf and root extracts on percentage organ to body ratio

Rats treated with OIL200, OIR200 and OIR400 had significantly larger hearts $(\mathrm{p}<0.01)$ compared to those from the NT group. Hearts from rats treated with OIR were even bigger $(\mathrm{p}<0.05)$ than those from the LN control group while hearts from OIL400 and amlodipine group were not significantly different from the NT group. Kidneys from OIL200, OIR200 and OIR400 groups were smaller $(\mathrm{p}<0.01)$ than those from the NT group. Kidneys from OIL400 and amlodipine treatment groups were not significantly different from those from the NT control group. The liver from OIR400 treatment group was significantly $(\mathrm{p}<0.05)$ smaller than the NT and LN control groups (Table 7).

Table 4: Effect of $O$. imbricatum extracts on diastolic blood pressure in L-NAME induced hypertension (mmHg).

\begin{tabular}{|c|c|c|c|c|c|c|c|c|}
\hline \multirow{3}{*}{ Treatment Groups } & \multicolumn{8}{|c|}{ Time (weeks) } \\
\hline & \multicolumn{4}{|c|}{ L-NAME only } & \multicolumn{4}{|c|}{ L-NAME + treatment } \\
\hline & Wk1 & Wk2 & Wk3 & Wk4 & Wk5 & Wk6 & Wk7 & Wk8 \\
\hline NT & $111 \pm 4$ & $111 \pm 4$ & $108 \pm 3$ & $108 \pm 3$ & $108 \pm 3$ & $122 \pm 4$ & $123 \pm 3$ & $123 \pm 3$ \\
\hline $\mathrm{LN}$ & $109 \pm 1$ & $\underset{\# \#}{153 \pm 2}$ & $\underset{\# \#}{165 \pm 3}$ & $\underset{\# \#}{162 \pm 6}$ & 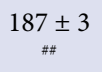 & $\underset{\# \#}{206 \pm 1}$ & $171_{\# \#} \pm 3$ & $\underset{\# \#}{190 \pm 2}$ \\
\hline AMLO & $124 \pm 2$ & $\underset{\# \#}{154 \pm 3}$ & $\underset{\# \#}{166 \pm 4}$ & $\underset{\text { \#\# }}{177 \pm 3}$ & $177 \pm 4$ & $148 \pm 3$ & $141 \pm 3$ & $\underbrace{125 \pm 2}_{* * \# \#}$ \\
\hline OIL200 & $119 \pm 3$ & $\underset{\# \#}{148 \pm 2}$ & $\underset{\# \#}{168 \pm 4}$ & $167 \pm 4$ & $\underset{\sharp \#}{184 \pm 3}$ & $\underbrace{173 \pm 6}_{* * * \#}$ & $170 \pm 4$ & $\underset{* * \# \#}{158 \pm 4}$ \\
\hline OIL400 & $126 \pm 3$ & $\underset{\# \#}{166 \pm 4}$ & $\underset{\ldots \#}{166 \pm 2}$ & $165 \pm 2$ & $\underset{\substack{\# \# \\
184}}{183}$ & $\underset{* * * \#}{158 \pm 4}$ & $151 \pm 6$ & $\begin{array}{c}139 \pm 4 \\
* *\end{array}$ \\
\hline OIR200 & $125 \pm 3$ & $\underset{\# \#}{149 \pm 1}$ & $\underset{\# \#}{163 \pm 1}$ & $173 \pm 3$ & $177 \pm 4$ & $\underset{* * \# \#}{170 \pm 3}$ & $157 \pm 5$ & $162 \pm 4$ \\
\hline OIR400 & $119 \pm 3$ & $161 \pm 3$ & $179 \pm 1$ & $171_{\# \#} \pm 4$ & $174 \pm 3$ & $167 \pm 5$ & $150 \pm 2$ & $169 \pm 3$ \\
\hline
\end{tabular}

Values are expressed as mean $\pm \mathrm{SEM}$. NT $=$ normotensive normal saline; $\mathrm{LN}=\mathrm{L}$-Name/normal saline; $\mathrm{OIL}=$ O. imbricatumleaf extract; OIR $=$ O. imbricatumroot extract; AMLO $=$ amlodipine. $n=6 ;{ }^{*}$ indicates comparison between the treatment group and L-NAME (LN) control group; \# indicates comparison between the treatment group and normotensive control group $(\mathrm{NT}) .{ }^{*} \mathrm{p}<0.05,{ }^{* *} \mathrm{p}<0.01 ;{ }^{*} \mathrm{p}<0.05,{ }^{* *} \mathrm{p}<0.01$

Table 5: Effect O. imbricatum extracts on Heart rates (bpm).

\begin{tabular}{ccccccccc}
\hline & \multicolumn{3}{c}{ L-NAME Only (Induction of HTN) } & \multicolumn{3}{c}{ L-NAME +Medication } \\
& WK1 & WK2 & WK3 & WK4 & WK5 & WK6 & WK7 & WK8 \\
\hline NT & $413 \pm 3$ & $413 \pm 3$ & $408 \pm 4$ & $408 \pm 4$ & $406 \pm 4$ & $406 \pm 4$ & $413 \pm 5$ & $413 \pm 5$ \\
LN & $391 \pm 4$ & $363 \pm 5^{* *}$ & $368 \pm 2^{*}$ & $356 \pm 2^{* *}$ & $391 \pm 5$ & $362 \pm 6^{\# *}$ & $381 \pm 2$ & $386 \pm 4$ \\
AMLO & $402 \pm 8$ & $372 \pm 6^{*}$ & $366 \pm 3^{* *}$ & $362 \pm 4^{* *}$ & $344 \pm 7$ & $354 \pm 3$ & $398 \pm 5^{* *}$ & $382 \pm 2^{* *}$ \\
OIL200 & $411 \pm 5$ & $366 \pm 4^{* *}$ & $387 \pm 5^{*}$ & $362 \pm 5^{* *}$ & $377 \pm 6$ & $382 \pm 8$ & $423 \pm 5^{* *}$ & $393 \pm 4$ \\
OIL400 & $385 \pm 1$ & $366 \pm 3^{* *}$ & $384 \pm 2$ & $390 \pm 3$ & $379 \pm 3$ & $360 \pm 6$ & $394 \pm 4$ & $409 \pm 4^{* *}$ \\
OIR200 & $402 \pm 6$ & $389 \pm 4$ & $381 \pm 4^{*}$ & $385 \pm 2$ & $396 \pm 10$ & $414 \pm 6$ & $420 \pm 4$ & $487 \pm 2$ \\
OIR400 & $385 \pm 6$ & $383 \pm 7$ & $377 \pm 6$ & $371 \pm 5$ & $354 \pm 4$ & $407 \pm 5^{\# *}$ & $386 \pm 3^{\# *}$ & $376 \pm 2^{*}$
\end{tabular}

Values are expressed as mean $\pm \mathrm{SEM} . \mathrm{NT}=$ normotensive normal saline; $\mathrm{LN}=\mathrm{L}$-Name/normal saline; $\mathrm{OIL}=$ O. imbricatumleaf extract; OIR $=$ O. imbricatumroot extract; $\mathrm{AMLO}=$ amlodipine. $\mathrm{n}=6$; ${ }^{*}$ indicates comparison between baseline heart rate and weekly heart rates. ${ }^{*} \mathrm{p}<0.05,{ }^{* *} \mathrm{p}<0.01 ;{ }^{*}$ indicates comparison between baseline (wk5) heart rate and weekly heart rates. ${ }^{*} \mathrm{p}<0.05,{ }^{* \#} \mathrm{p}<0.01$

Table 6: Effect of $O$. imbricatum extracts on urine output $(\mathrm{mL})$.

\begin{tabular}{ccccccccc}
\hline Wk & NT & LN & AMLO & OIL200 & OIL400 & OIR200 & OIR400 \\
\hline 5 & $10 \pm 0.6$ & $16 \pm 0.5$ & $12 \pm 0.1$ & $17 \pm 2$ & $14 \pm 1.7$ & $16 \pm 1.2$ & $19 \pm 1.6^{* *}$ \\
6 & $9 \pm 0.3$ & $23 \pm 1.6^{* *}$ & $11 \pm 0.6^{* *}$ & $20 \pm 1.9^{* *}$ & $14 \pm 1^{* *}$ & $15 \pm 0.3$ & $17 \pm 1.7^{* *}$ \\
7 & $11 \pm 0.4$ & $19 \pm 1^{* *}$ & $12 \pm 1^{* *}$ & $17 \pm 1.9^{*}$ & $16 \pm 0.6^{*}$ & $17 \pm 0.7^{*}$ & $17 \pm 1.3^{*}$ \\
8 & $11 \pm 0.4$ & $18 \pm 1^{* *}$ & $18 \pm 0.4^{* *}$ & $20 \pm 1.7^{* *}$ & $19 \pm 1.2^{* *}$ & $13 \pm 0.3$ & $19 \pm 1.2^{* *}$
\end{tabular}

Values are expressed as mean \pm SEM. NT = normotensive normal saline; $\mathrm{LN}=\mathrm{L}-\mathrm{Name} /$ normal saline; $\mathrm{OIL}=0$. imbricatumleaf extract; $\mathrm{OIR}=0$. imbricatumroot extract; $\mathrm{AMLO}=$ amlodipine. $\mathrm{n}=6$; ${ }^{*}$ indicates comparison between the treatment groups and L-NAME (LN) control group; ${ }^{*}$ indicates comparison between the treatment groups and normotensive control group (NT). ${ }^{*} p<0.05,{ }^{* *} p<0.01 ;{ }^{*} p<0.05,{ }^{\# *} p<0.01$

Table 7: Percentage organ to body weight ratio after treatment with 0 . imbricatum extracts.

\begin{tabular}{ccccccccc}
\hline Organ & NT & LN & AMLO & OIL200 & OIL400 & OIR200 & OIR400 \\
\hline Heart (\%) & $0.37 \pm 0.01$ & $0.4 \pm 0.01$ & $0.37 \pm 0.01$ & $0.42 \pm 0.01^{* *}$ & $0.4 \pm 0.01$ & $0.44 \pm 0.01^{* * *}$ & $0.45 \pm 0.01^{* * *}$ \\
Kidney (\%) & $0.59 \pm 0.005$ & $0.54 \pm 0.01^{\# *}$ & $0.57 \pm 0.003$ & $0.55 \pm 0.01^{* *}$ & $0.59 \pm 0.004^{* *}$ & $0.55 \pm 0.01^{* *}$ & $0.54 \pm 0.01^{* *}$ \\
Liver (\%) & $2.53 \pm 0.3$ & $2.47 \pm 0.05$ & $2.52 \pm 0.01$ & $2.56 \pm 0.03$ & $2.45 \pm 0.03$ & $2.45 \pm 0.01$ & $2.34 \pm 0.02^{* *}$ \\
\hline
\end{tabular}

Values are expressed as mean \pm SEM. NT $=$ normotensive normal saline; $\mathrm{LN}=\mathrm{L}-\mathrm{Name} /$ normal saline; $\mathrm{OIL}=\mathrm{O}$. imbricatumleaf extract; OIR $=$ O. imbricatum root extract; $\mathrm{AMLO}=$ amlodipine. $\mathrm{n}=6$; ${ }^{*}$ indicates comparison between the treatment group and L-NAME (LN) control group; * indicates comparison between the treatment group and normotensive control group (NT). ${ }^{*} \mathrm{p}<0.05,{ }^{* *} \mathrm{p}<0.01 ;{ }^{*} \mathrm{p}<0.05,{ }^{* * *} \mathrm{p}<0.01$ 


\section{DISCUSSION}

This study examined the antioxidant capacity and antihypertensive effects of the hydroethanolic extracts of Osteospermum imbricatum in spontaneously hypertensive rats (SHR) and L-NAME induced hypertensive rats. The findings demonstrate that $O$. imbricatum has radical scavenging properties due to the presence of flavonoids and phenolic compounds. The study confirmed that L-NAME induced HTN exhibits a marked elevation of SBP and DBP which is sustained by continues administration of L-NAME throughout the treatment period. The extracts showed mild positive antihypertensive effects in the two hypertensive rat models that were used in the study.

Free radicals are known to play a definite role in a wide variety of pathological conditions. Antioxidants scavenge free radicals and protect the body from oxidative stress and consequently chronic diseases. ${ }^{16}$ Phenolic compounds of plants have hydroxyl groups that confer scavenging ability and retard oxidative degradation of lipids thus improving the quality and nutritional value of plant products. ${ }^{17}$ Flavonoids are naturally occurring in plants and are thought to have positive effects on human health. They have been shown to be highly effective scavengers of most oxidizing molecules, including singlet oxygen, and various free radicals implicated in several diseases. ${ }^{12}$

Results from the DPPH assay indicated that the leaf extract had lower absorbance and hence lower $\mathrm{IC}_{50}$ values compared to the root extract indicating that the leaf extract had better free radical scavenging activity. This was supported by its higher ABTS activity and better ability to reduce ferric complex to the ferrous form compared to the root extract. This indicates that the leaf extract had higher antioxidant capacity compared to the root extract reason being that it had more phenols and flavonoid compounds.

High blood pressure and decreased heart rates induced by chronic blockade of nitric oxide synthesis using L-NAME were observed in this study. This study has shown that daily administration of L-NAME for 4 weeks caused the development of HTN. This finding is consistent with previous studies ${ }^{18}$ which showed that daily L-NAME treatment for four weeks produces a marked elevation of blood pressure and probably vascular resistance.

Osteospermum imbricatum extract mildly but significantly reduced blood pressures in both SHRs and L-NAME models. Its mild effect may be due to the fact that in this study it was used singly while in traditional practice, it is used in combination with other plants. There are reports of synergy between extracts of different plants which are traditionally combined although mechanism of synergy is not clear. ${ }^{19}$ The excessive production of ROS is proposed to be a major factor mediating the pathogenesis of hypertension in these models. It is suggested that a large quantity of superoxide production suppresses nitric oxide bioavailability in the L-NAME model. ${ }^{20}$ Lack of nitric oxide in the circulatory system induces vasoconstriction, increase in peripheral resistance and eventually leading to HTN. The leaf extract may have exhibited its blood pressure lowering properties by up-regulating NO synthase or serving as a NO donor. Nitric oxide is a potent vasodilator, it maintains vascular tone, inhibit platelet aggregation, monocyte adhesion, smooth muscle proliferation/migration thus preventing endothelial dysfunction. ${ }^{21}$ Availability of $\mathrm{NO}$ will decrease peripheral resistance and hence blood pressure. The decrease in heart rates may be due baroreflex activity suggesting that L-NAME-induced increase in total peripheral resistance may result in stimulation of baroreceptors and subsequent decrease in heart rates. This finding is consistent with other studies ${ }^{22}$ which explained that the rise in blood pressure due to NO deficiency activates baroreceptors of the afferent arterioles resulting in both direct and indirect activation of the parasympathetic innervation of the heart thus decreasing heart rates.
The pharmacological actions of herbs or herbal isolates appear to favourably modulate several parameters implicated in the pathogenesis of blood pressure, including but not limited to reactive oxygen species production, vascular smooth muscle cell phenotype, endothelial function, platelet activation, pro-inflammatory signalling, and gene expression. ${ }^{23}$ Herbal medicines usually tend to have several broad complementary or synergistic actions on physiological systems and are often non-specific. While synthetic drugs address symptoms caused by specific diseases as understood by scientific pathology herbal medicines usually direct towards aiding the body's own healing process. ${ }^{24}$ Although most antihypertensive herbs have broad spectrum of action and are considered safe, it is important to note that some herbal therapy of HTN have adverse effects ${ }^{23}$ for instance O. imbricatum is toxic at high concentrations $\left(3807 \mathrm{mg} / \mathrm{kg} \mathrm{LD}{ }_{50}\right) \cdot{ }^{15}$

The diuresis observed 4 weeks after treatment with L-NAME may be associated with HTN induced kidney disease. The renin angiotensin system is upregulated in L-NAME models and angiotensin II is involved in the progression of cardiac hypertrophy and chronic renal disease. ${ }^{25}$ Although the hearts from groups treated with L-NAME increased, it is difficult to draw a conclusion on cardiac hypertrophy since only the percentage heart to body weight ratios were measured in this study.

\section{CONCLUSION}

The present study suggests that $O$. imbricatum has antioxidant effects and can mildly treat HTN. Further studies are needed to determine the mechanism of action of $O$. imbricatum in lowering blood pressure and isolation of the antihypertensive bioactive compounds present in the plant which may be more effective.

\section{ACKNOWLEGEMENT}

This work was supported by a grant from the National Research Foundation (NRF Grant No: 93177), South Africa and in part by the National Institute of Minority Health and Health Disparities/National Institutes of Health (Grant \# 5T37MD001810).

\section{CONFLICTS OF INTEREST}

None.

\section{REFERENCES}

1. Khan MI, Mohammad A, Patil G, Naqvi SAH, Chauhan LKS, Ahmad I. Induction of ROS, mitochondrial damage and autophagy in lung epithelial cancer cells by iron oxide nanoparticles. Biomaterials. 2012;33(5):1477-88.

2. Gonzalez J, Valls N, Brito R, Rodrigo R. Essential hypertension and oxidative stress: New insights. World J Cardiol. 2014;6(6):353-66.

3. Virdis A, Duranti E, Taddei S. Oxidative stress and vascular damage in hypertension: Role of angiotensin ii. Int J Hypertens. 2011;2011.

4. Kaur M, Rana AC, Kumar S. www.ijpbs.com Induction of hypertension by various animal models. Int J Pharm Biol Sci. 2011;1(3):2230-7605.

5. Maneesai P, Prasarttong P, Bunbupha S. Synergistic Antihypertensive Effect of Carthamus tinctorius L. Extract and Captopril in L-NAMEInduced Hypertensive Rats via Restoration of eNOS and $A T_{1} R$ Expression. Nutrients. 2016;8(3):122

6. Pakdeechote P, Kukongviriyapan U, Berkban W, Prachaney P. Mentha cordifolia extract inhibits the development of hypertension in L-NAMEinduced hypertensive rats. J Med Plants Res. 2011;5(7):1175-83.

7. Antoniou S, Saxena M, Hamedi N. Management of Hypertensive Patients With Multiple Drug Intolerances: A Single-Center Experience of a Novel Treatment Algorithm. J Clin Hypertens. 2016;18(2):129-38.

8. Mugabo P, Raji IA. Effects of aqueous leaf extract of Asystasia gangetica on the blood pressure and heart rate in male spontaneously hypertensive Wistar rats. BMC Complement Altern Med. 2013;13(1):283. 
9. Olorunnisola OS, Bradley G, Afolayan AJ, O.S. O, G. B, A.J. A. Ethnobotanical information on plants used for the management of cardiovascular diseases in NKonkobe municipality, South Africa. J Med Plant Res. 2011;5(17):4256-60.

10. South African National standards. SANS 10386:2008 - The care and use of animals for scientific purposes. SABS Stand Div. 2008:1-43.

11. Irshad M, Zafaryab M, Singh M, Rizvi MMA. Comparative Analysis of the Antioxidant Activity of Cassia fistula Extracts. Int J Med Chem. 2012;2012:1-6.

12. Saeed N, Khan MR, Shabbir M. Antioxidant activity, total phenolic and total flavonoid contents of whole plant extracts Torilis leptophylla $L$. BMC Complement Altern Med. 2012;12(1):221.

13. Tata CM, Sewani-Rusike CR, Oyedeji OO, Gwebu ET, Nkeh-Chungag BN. Renoprotective effects of the hydroethanolic extract of Senecio serratuloides against Nw -Nitro L-arginine Methyl Ester-induced oxidative stress in wistar rats. Pharmacogn Mag. 2020;16:S418-24.

14. Tata CM, Gwebu ET, Olasunkanmi AO. Acute toxicity and antihypertensive effects of Artemisia afra and Leonotis leonurus in spontaneously hypertensive rats. Res J Biotechnol. 2018;13(1):20-5.

15. Tata CM, Gwebu ET, Aremu OO. Acute toxicity study and prevention of $\mathrm{N} \omega$-nitro-l-arginine methyl ester-induced hypertension by osteopermum imbricatum. Trop J Pharm Res. 2018;17(6):1111-8.

16. Sinha N, Dabla PK. Oxidative stress and antioxidants in hypertension-a current review. Curr Hypertens Rev. 2015;11(2):132-42.
17. Arnao MB, Cano A, Acosta M. The hydrophilic and lipophilic contribution to total antioxidant activity. Food Chem. 2001;73(2):239 44

18. Sozer V, Uzun H, Gelisgen R. The effects of atorvastatin on oxidative stress in L-NAME-treated rats. Scand J Clin Lab Invest. 2013;73(7):5917.

19. Rasoanaivo P, Wright CW, Willcox ML, Gilbert B. Whole plant extracts versus single compounds for the treatment of malaria: synergy and positive interactions. Malar J. 2011;10(1):S4

20. Berkban T, Boonprom P, Bunbupha S. Ellagic Acid Prevents L-NAMEInduced Hypertension via Restoration of eNOS and p47phox Expression in Rats. Nutrients. 2015;7(7):5265-80.

21. Kung CF, Moreau P, Takase $H$, LuscherTF. L-NAME hypertension alters endothelial and smooth muscle function in rat aorta. Prevention by trandolapril and verapamil. Hypertens (Dallas, Tex 1979) 1995:26(5):744-51.

22. Fellet $A L$, Di Verniero $C$, Arza P. Effect of acute nitric oxide synthase inhibition in the modulation of heart rate in rats. Brazilian $\mathrm{J}$ Med Bio Res $=$ Rev Bras Pesqui medicas e Biol. 2003:36(5):669-76.

23. Al Disi SS, Anwar MA, Eid AH. Anti-hypertensive Herbs and their Mechanisms of Action: Part I. Front Pharmacol. 2016:6:323.

24. Karimi A, Majlesi M, Rafieian-Kopaei M. Herbal versus synthetic drugs; beliefs and facts. J nephropharmacology. 2015;4(1):27-30

25. Crowley SD, Gurley SB, Herrera MJ. Angiotensin II causes hypertension and cardiac hypertrophy through its receptors in the kidney. Proc Natl Acad Sci USA. 2006;103(47):17985-90.

\section{GRAPHICAL ABSTRACT}

\section{Antioxidant and Antihypertensive Effects of Osteospermum imbricatum}

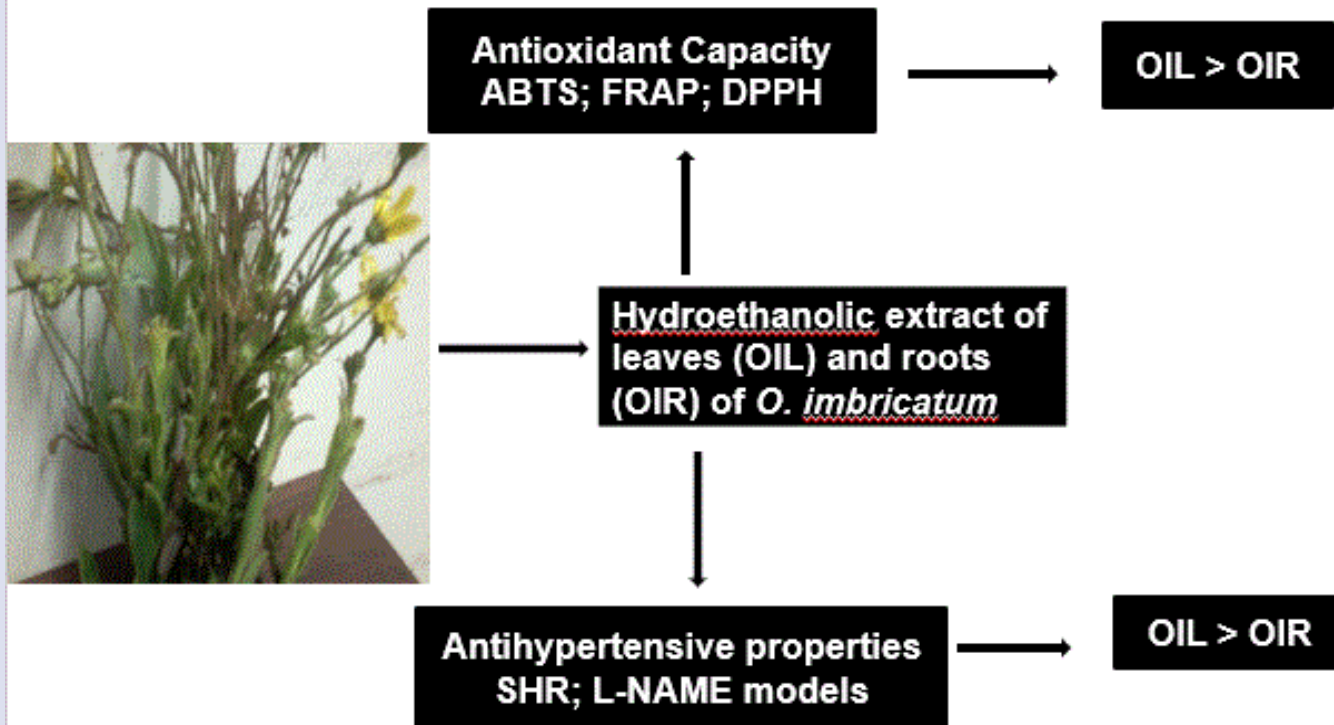




\section{ABOUT AUTHORS}

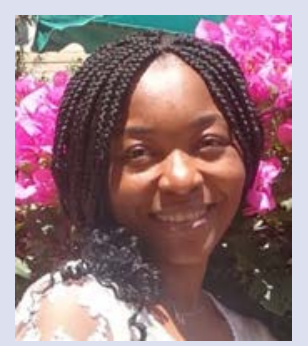

\section{Charlotte Mungho Tata (PhD)}

Charlotte MunghoTata is a Postdoctoral Fellow at the Faculty of Science, University of Johannesburg. She has a PhD in Physiology from Walter Sisulu University. Her research focus is non-communicable diseases especially hypertension.

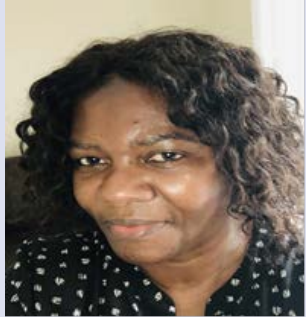

\section{Prof Constance Rufaro Sewani-Rusike}

My primary research interests are the pathophysiology of obesity and metabolic syndrome (MetS). The effects and mechanism of action of medicinal plants as potential therapeutic interventions for the prevention and treatment of obesity, MetS and associated complications are the main animal studies in our lab. Human studies, involve examining the role of gut permeability, inflammation and oxidative stress in these pathologies. Prof Constance R. Sewani-Rusike holds MBChB (University of Zimbabwe) and PhD (Michigan State University, East Lansing, USA).

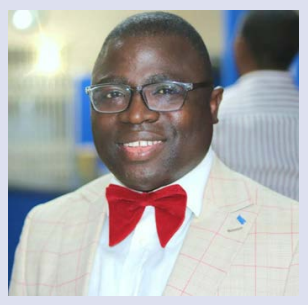

\section{Olukayode Aremu}

Olukayode Aremu holds an MSc degree in Physiological Sciences, where he explored the antihypertensive and antioxidant properties of some medicinal plants in hypertension using different animal models. He is also interested in characterising the phenotypes of inflammation, fibrosis and remodelling in patients diagnosed with rheumatic heart disease (RHD), using cardiovascular magnetic resonance and autophagy markers (understanding the inflammatory pathway in the autoimmune involvement in the pathogenesis of RHD). This is to corroborate his keen interest to discontinue the existence of high mortality and debilitating conditions associated with RHD.

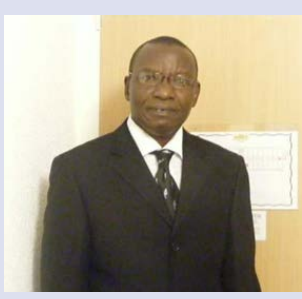

\section{Prof Opeoluwa Oyehan Oyedeji}

Opeoluwa O. Oyedeji is an Associate Professor of organic chemistry at the University of Fort Hare. He obtained his PhD in organic chemistry from University of KwaZulu-Natal, South Africa in 2010. $\mathrm{He}$ is C3 NRF rated researcher.

His research areas of interest include isolation of natural product (terpenoids) which are bioactive with pharmacophore groups for enhanced biological activities in drug discovery. His research interest also extend into identifying, isolation, characterization of essential oils from medicinal plant for economic and medicinal potential which involves finding its usage and formulation in nanoparticles for drug therapy.

He has been teaching chemistry in tertiary institution for over 25 years and he has supervised both undergraduate and postgraduate research projects in the field of organic and environmental chemistry.

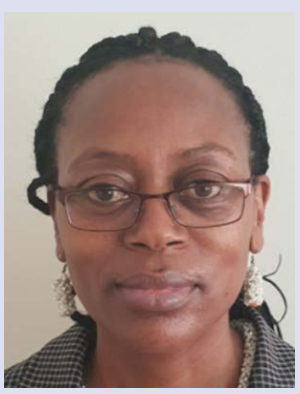

\section{Prof Benedicta Ngwenchi Nkeh-Chungag}

She seeks to understand the contribution of various cadiometabolic risk factors to the development of related diseases while exploring the use of medicinal plants to address them.

Cite this article:Tata CM, Sewani-Rusike CR, Aremu O, Oyedeji OO, Nkeh-Chungag BN. Antihypertensive Effects of Osteospermum Imbricatum in Two Hypertensive Rat Models. Pharmacog J. 2021;13(3): 744-51. 